\title{
Resolution of Intrabiliary Ruptured Hepatic Hydatid Cyst after Endoscopic Extraction: Case Report
}

\section{Ashraf Abdel Azeem M*}

Department of General Surgery, Minia University Hospital, Minia city, Egypt

*Corresponding author: Ashraf Abdel Azeem Mohamed, Department of General Surgery, Minia University Hospital, Minia city, Postal code 61111, Egypt, Tel: 0020102554076; E-mail: ashraf.azeem@yahoo.com

\section{Case Report \\ Volume 1 Issue 3}

Received Date: September 19, 2017

Published Date: October 12, 2017

DOI: $10.23880 /$ mjccs- 16000113

\section{Abstract}

Hepatic hydatid cyst may rupture into bile ducts in $4-20 \%$ of cases leading to cholestasis in $2 / 3$ of cases. We tried to prove that ERCP can replace surgery in treatment of intrabiliary ruptured hydatid cyst. Our patient was 42 years old male with cholestasis, abdominal ultrasonography showed hypoechoic lesion at postero-inferior aspect of right lobe related to dilated CBD, total bilirubin $26.1 \mathrm{mg} / \mathrm{dl}$, direct bilirubin $18.8 \mathrm{mg} / \mathrm{dl}$. MDCT revealed ovoid cystic lesion in right lobe, serology for hydatid was positive. Cyst was seen communicating with confluence of hepatic ducts. During ERCP, membranes were seen coming out of papilla of Vater, on injection of contrast; communication of biliary tree with cyst was established. Endoscopic papillotomy was performed and cannulation of bile duct reached abscess cavity with aspiration of yellowish green fluid, bacteriological examination of this fluid showed pseudomonas aeruginosa. Large amount of membranes were removed from CBD and sent for histopathology which showed picture of hydatid cyst. Procedure was completed with CBD stenting. Single course of Albendazole was given. Follow up after one month showed marked improvement of patient's general condition with drop of TLC and bilirubin. Follow up MDCT showed marked regression in size of previously described lesion. One month later, additional drop of bilirubin was achieved. Abdominal ultrasonography showed complete resolution of cyst confirmed by ERCP revealing start of cyst calcification with obliteration of its cavity and stent was removed. We concluded that therapeutic ERCP may replace surgery in treatment of intrabiliary rupture of hepatic hydatid cyst.

Keywords: Ecchinococcus; Endoscopic Cholangiography; Liver Cyst; Hydatid; Biliary Fistula

\section{Introduction}

In sheep-rearing areas, especially in Mediterranean countries, hydatid disease is endemic. Hydatid disease is caused by the larval stage of echinococcus granulosus [1]. Rupture of hepatic hydatic cysts into the biliary tree accounts for $4-20 \%$ of cases, either spontaneously or following surgery lead to cholestasis in over two thirds of these cases [2,3-5]. Diagnosis of this complication was made previously at laparatomy and treated surgically $[6,7]$. ERCP is of value in such cases for diagnostic and therapeutic purposes $[8,9]$. After reviewing the literature, 


\section{Medical Journal of Clinical Trials \& Case Studies}

we found few cases of ruptured hepatic hydatid cyst into the biliary tree which were completely treated by ERCP and adjuvant medical therapy [10]. This case report documents a patient with ruptured hepatic hydatid cyst into the biliary tree and treated by ERCP with adjuvant Albendazole [11].

\section{Case Report}

A forty two year old male patient, from Upper Egypt, presented to Tropical Medicine Department, Minia University Hospital, at 13/8/2010 with history of high fever $\left(39^{\circ} \mathrm{C}\right)$ and right hypochondrial pain of one and half months duration. The patient was jaundiced and had tender hepatomegaly. There is history of working in Jordan for 5 years. Investigations showed a disturbed liver function with total bilirubin of $16.7 \mathrm{mg} / \mathrm{dl}$ and direct of $10.6 \mathrm{mg} / \mathrm{dl}$ (Laboratory data shown in table 1 ).

\begin{tabular}{|c|c|}
\hline Investigation & Result \\
\hline T Bil & $16.7 \mathrm{mg} / \mathrm{dl}$ \\
\hline D Bil & $10.6 \mathrm{mg} / \mathrm{dl}$ \\
\hline K & $2.7 \mathrm{mmol} / \mathrm{l}$ \\
\hline Na & $136 \mathrm{mmol} / \mathrm{l}$ \\
\hline RBS & $95 \mathrm{mg} / \mathrm{dl}$ \\
\hline Urea & $53 \mathrm{mg} / \mathrm{dl}$ \\
\hline Creatinine & $1 \mathrm{mg} / \mathrm{dl}$ \\
\hline ALT & $54 \mathrm{U} / \mathrm{l}$ \\
\hline AST & $86 \mathrm{U} / \mathrm{l}$ \\
\hline T Prot & $6.1 \mathrm{~g} / \mathrm{dl}$ \\
\hline ALB & $2.7 \mathrm{~g} / \mathrm{dl}$ \\
\hline PT & $13.8 \mathrm{sec}$ \\
\hline PC & $80 \%$ \\
\hline HB & $14.2 \mathrm{~g} / \mathrm{dl}$ \\
\hline TLC & $24.000 \mathrm{Cells} /$ Cmm \\
\hline HCV & $+\mathrm{ve}$ \\
\hline HBV \& HIV & $-\mathrm{ve}$ \\
\hline ESR (1 ${ }^{\text {st }}$ and 2nd hours) & 110 and $125 \mathrm{~mm}$ respectively \\
\hline
\end{tabular}

Ultrasonography of abdomen reported mildly enlarged liver, course echopattern with well defined heterogeneous hypoechoic lesion at the postero-inferior aspect of right lobe intimately related to CBD measuring $7.2 \times 6.5 \mathrm{~cm}$, suggestive of liver abscess, CBD dilated about $2.5 \mathrm{~cm}$ till its pancreatic end, filled with mud seen within and is associated with mild IHBD, mildly enlarged spleen and minimal amount of free ascites. Percutaneous ultrasound guided aspiration of liver abscess was done with some improvement in the patient's general condition; medical treatment in the form of empirical antibiotics was given as the culture of aspirated fluid showed no growth on aerobic or aerobic media, cytology of aspirated fluid showed few pus cells and few epithelial cells. The patient again presented to the tropical medicine department after fifteen days at 28/8/2010 with history of fever, right hypochondrial pain and increased jaundice.

Investigations revealed a total bilirubin of $26.1 \mathrm{mg} / \mathrm{dl}$ (direct bilirubin $18.8 \mathrm{mg} / \mathrm{dl}$ ). MDCT scan was done revealing well defined large ovoid cystic lesion seen involving segment $\mathrm{V}$ and extending to segment VII of the right lobe (Figure 1), measuring about $8 \times 6.5 \times 8 \mathrm{~cm}$ in its largest dimensions, intravenous injection of contrast showed faint enhanced wall, this was associated with multiple tiny cystic lesions seen scattered at both hepatic lobes, mild IHBD with dilated CBD about $2 \mathrm{~cm}$ in diameter with thick biliary mud seen inside. Serology for hydatid was performed and was positive. The cyst was seen to communicate with the confluence of right and left hepatic ducts with dilatation of intra-hepatic biliary radicles (Figure 1). Minimal amount of free fluid collection related to lateral surface of right hepatic lobe, GB show thick enhanced wall denoting infection, cuts through lung bases show small segment of basal consolidation with mild right sided pleural effusion. The patient underwent ERCP.

Table 1: Laboratory data of the patient.
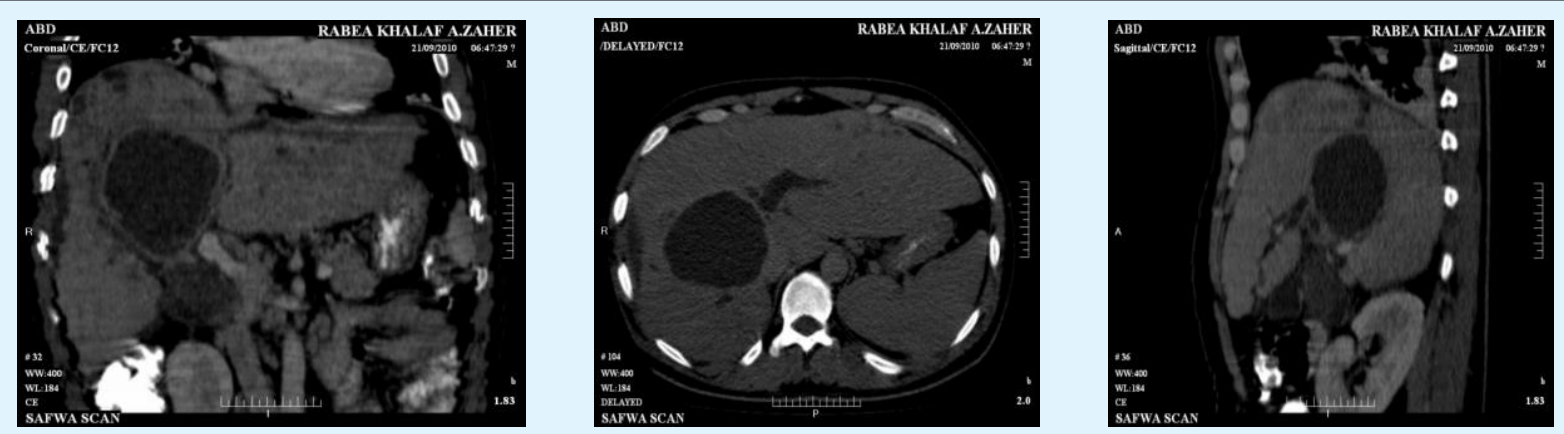

Figure 1: MDCT scan, cystic lesion communicating with hepatic duct. A) Transverse section B) Coronal section C) Sagittal section. 


\section{Medical Journal of Clinical Trials \& Case Studies}

During the procedure, membranes were seen to be coming out of papilla of Vater (Figure 2) and on injection of the contrast; communication of biliary tree with the

cyst was established with incomplete filling of CBD and cyst with dye (Figure 3).

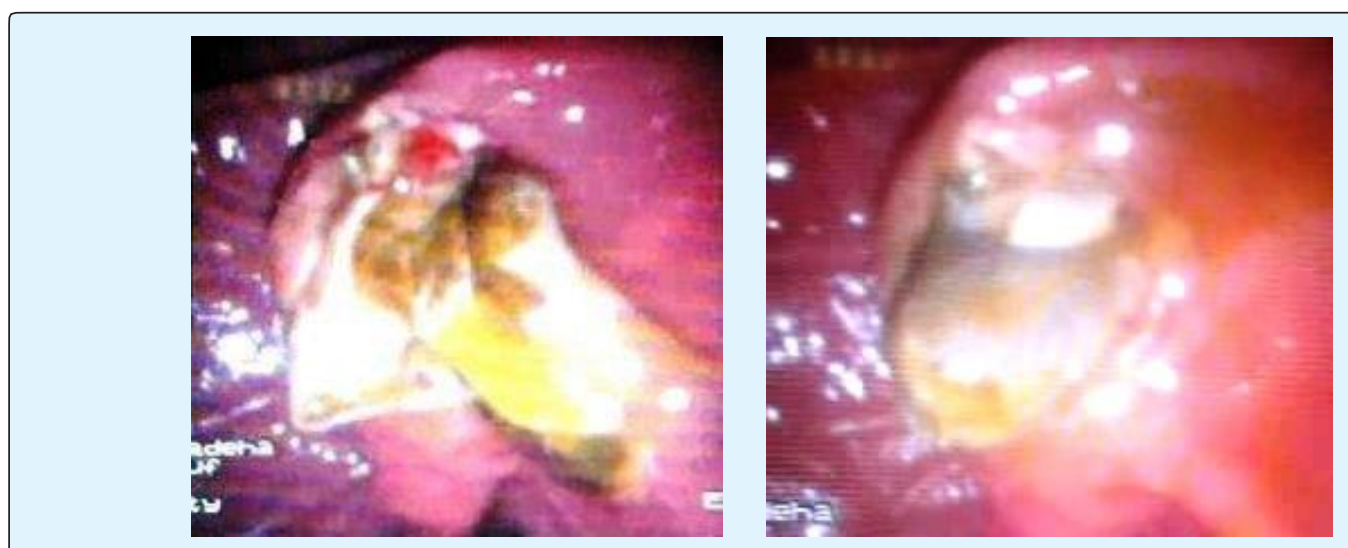

Figure 2: Endoscopic picture showing membranes were seen to be coming out of papilla of Vater.

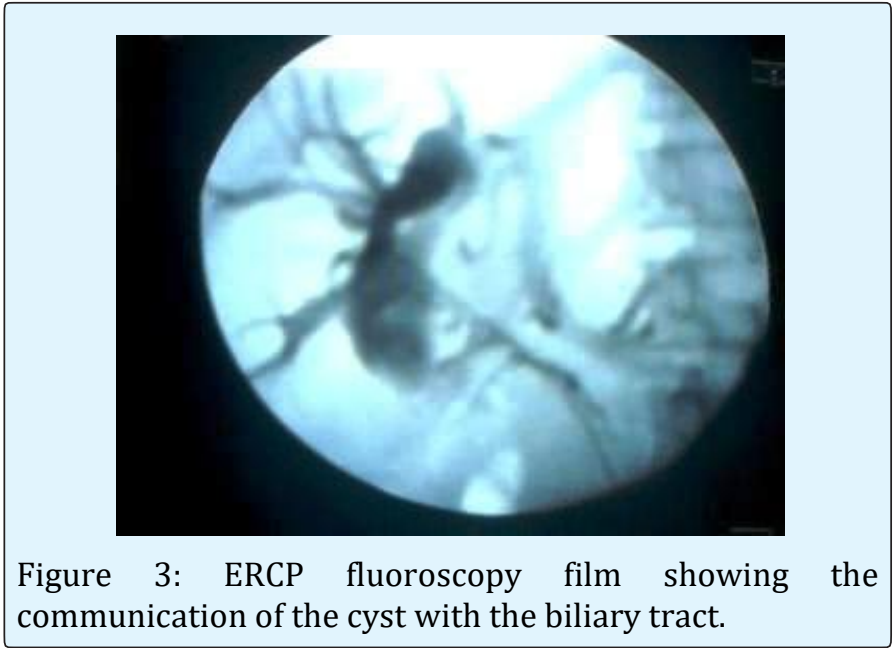

Endoscopic papillotomy was performed and cannulation of the bile duct reached the abscess cavity with aspiration of yellowish green infected fluid (Figure 4), bacteriological examination of this fluid showed pseudomonas aeruginosa. Also, large amount of membranes with leaf-like irregular appearance (Figure 5) were removed from the CBD using balloon (Figure 6) and Dormia basket (Figure 7) and sent for histopathology (Figure 8) which showed a picture of hydatid cyst with acellular laminated wall with no evidence of germinal membrane which may be lost due to secondary infection.

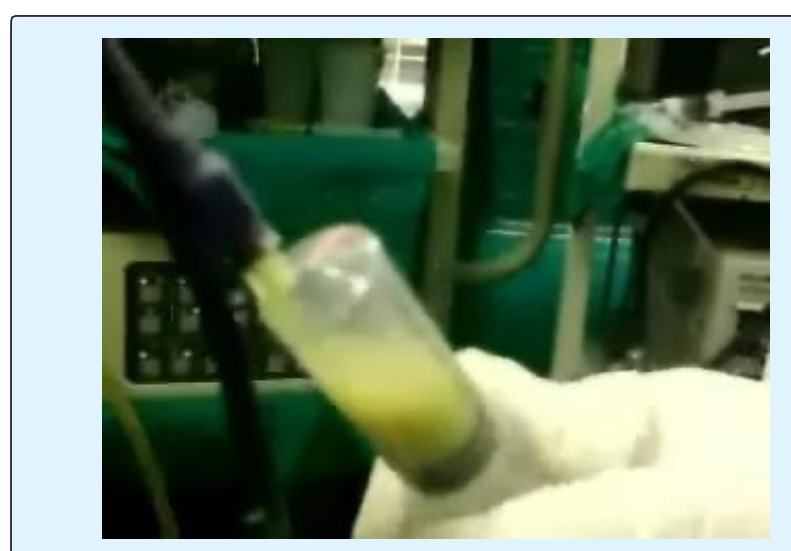

Figure 4: Aspiration of yellowish green infected fluid.
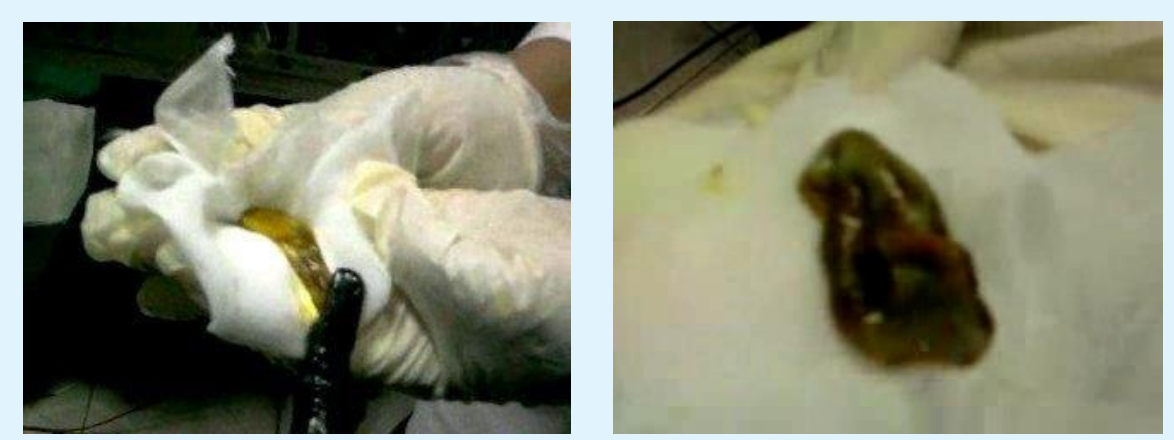

Figure 5: Membranes after removal with leaf-like irregular appearance. 


\section{Medical Journal of Clinical Trials \& Case Studies}

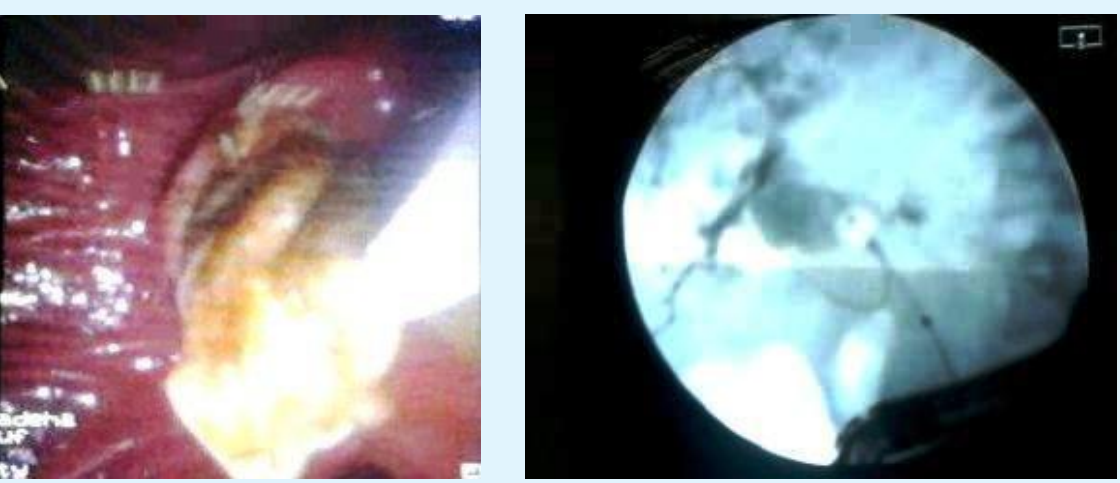

Figure 6: Endoscopic and fluoroscopic pictures showing removal of membranes from the CBD using balloon.
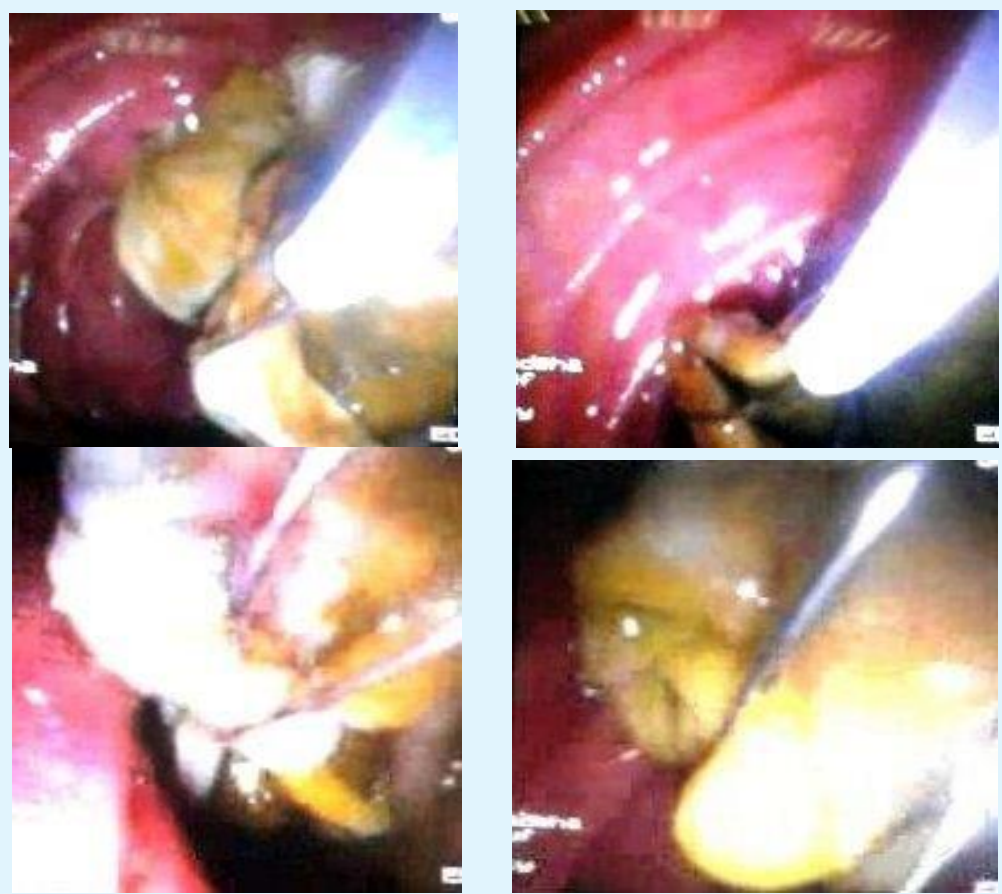

Figure 7: Endoscopic pictures showing removal of membranes from the CBD using Dormia basket.

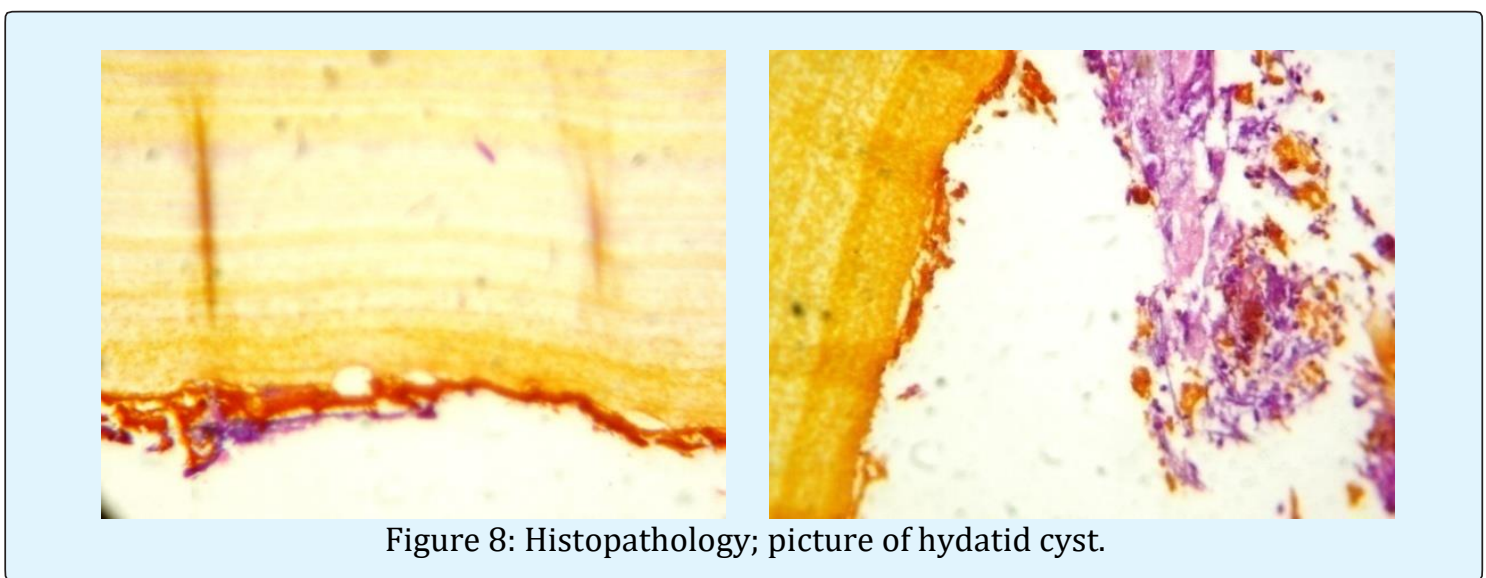




\section{Medical Journal of Clinical Trials \& Case Studies}

Cholangiography after removal of membranes revealed complete filling of the CBD and the cyst with the dye and communication of the cyst with the confluence of right and left hepatic ducts was established (Figure 9).

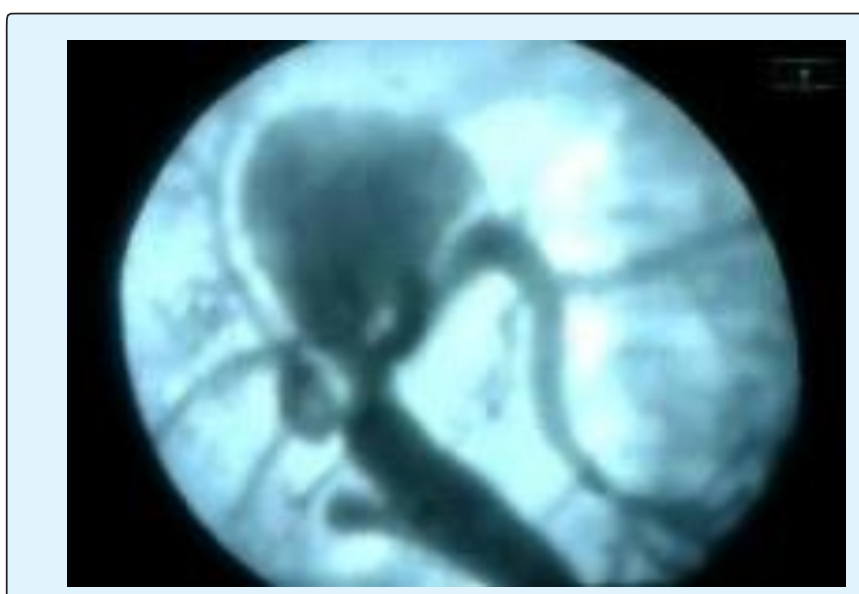

Figure 9: Fluoroscopic picture showing communication of the cyst with the confluence of left and right hepatic duct.

The procedure was completed with CBD stenting (Figure 10). The status of the cyst was followed up clinically and radiologically. Single course of Albendazole was given. Follow up after one month showed marked improvement of patient's general condition in the form of improvement of fever, pain and jaundice. Investigations revealed drop of TLC to 11,200 Cells/Cmm and drop of bilirubin with total bilirubin $11.2 \mathrm{mg} / \mathrm{dl}$ and direct 7.6 $\mathrm{mg} / \mathrm{dl}$. Follow up MDCT showed marked regression in the size of previously described lesion measuring now $5 \times 4.5$ $\mathrm{x} 4.5 \mathrm{~cm}$ in its maximum dimensions with air fluid level (Figure 11) and improvement of peri-lesional liver edema and complete disappearance of the multiple tiny cystic lesions scattered at both hepatic lobes seen in the previous MDCT. One month later, additional drop of bilirubin was achieved with total bilirubin $6.1 \mathrm{mg} / \mathrm{dl}$ and direct $4.3 \mathrm{mg} / \mathrm{dl}$. Abdominal Ultrasonography showed complete resolution of the cyst confirmed by ERCP which was done again revealing start of cyst calcification with obliteration of its cavity (Figure 12) and stent was removed.

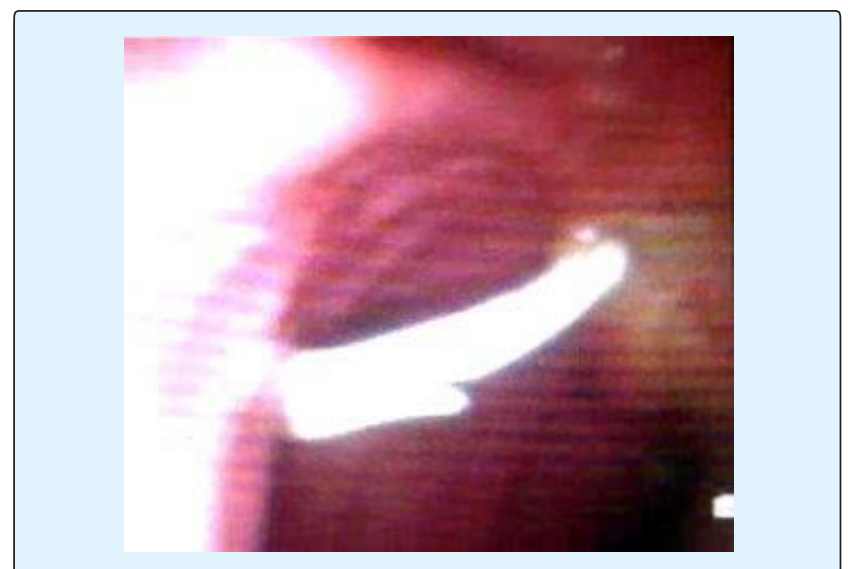

Figure 10: CBD stenting after removal of membranes.
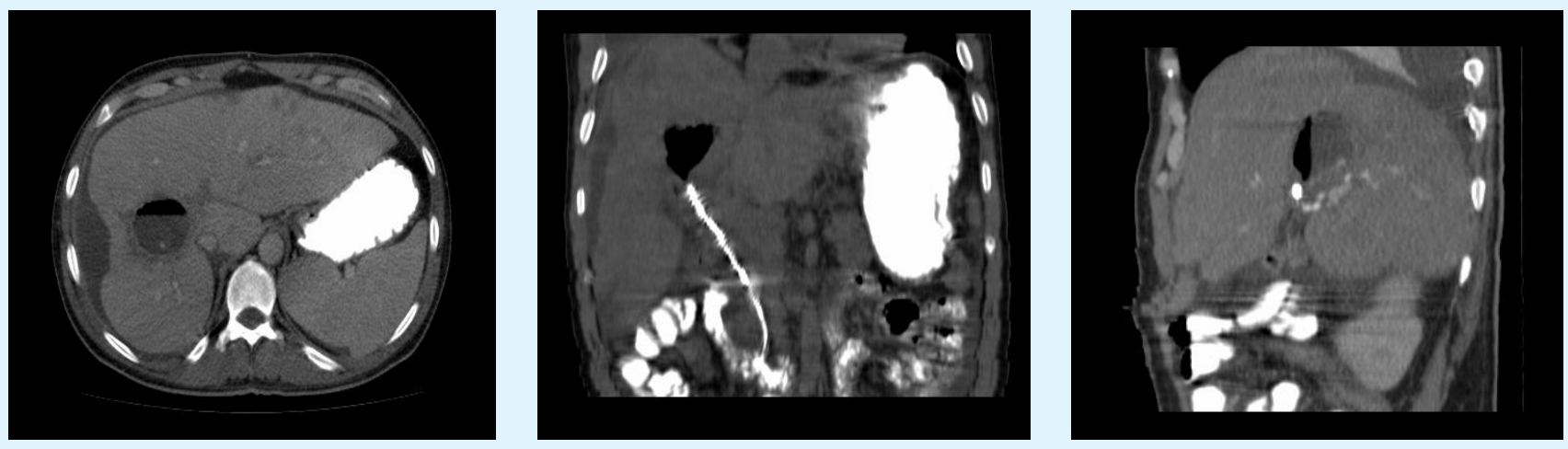

Figure 11: MDCT showed marked regression in the size of previously described lesion with stent seen in CBD reaching cyst cavity. 


\section{Medical Journal of Clinical Trials \& Case Studies}

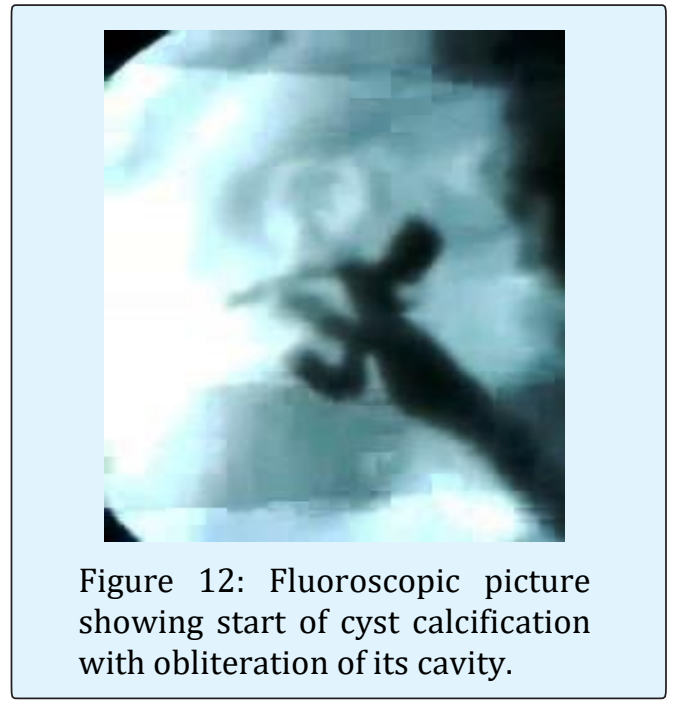

\section{Discussion}

Hydatid disease is an important health problem especially in endemic areas Beyrouti, Bouzidi. However, travelling to endemic areas makes hydatid disease seen more often in nonendemic areas causing diagnostic and operative challenge [12,13]. Intrabiliary rupture of hepatic hydatid cyst is one of the causes of cholestasis in endemic areas [2]. Most reported cases of intrabiliary rupture of hepatic hydatid cyst have been treated surgically with risk of mortality, morbidity and recurrence [14,15]. ERCP can be for diagnosis Vicente and treatment Dumas of intrabiliary rupture of hepatic hydatid cyst $[3,9,14-16]$. In this report, we can provide evidence that treatment by ERCP without surgery is effective. Al Karawi, et al repoted 5 cases of intrabiliary rupture of hepatic hydatid cyst treated by ERCP without surgery. So, ERCP can be successfully used to evacuate biliary daughter cysts and to irrigate the main cyst, resulting in complete cure of the disease $[11,17,18]$. In our case, there was clear communication between the main cyst and confluence of right and left hepatic ducts, complete evacuation of the hydatic cyst membranes was accomplished then irrigation was done. We used course of Albendazole for the multiple tiny cystic lesions described in the first MDCT, not for the ruptured cyst as recommended by Morris, because the contents of the cyst were evacuated as seen by MDCT scan done after ERCP which showed also reduction in the cyst size [19].

\section{Conclusion}

We concluded that therapeutic ERCP may replace for treatment of intrabiliary rupture of hepatic hydatid cyst as it is effective, safe and may achieve complete cure.

\section{References}

1. (1996) WHO Informal Working Group on Echinococcus Guidelines for treatment of cystic and alveolar echinococcus in humans. Bull World Health Organ 74: 234-242.

2. Galati G, Sterpetti AV, Caputo M, Adduci M, Lucandri G, et al. (2006) Endoscopic retrograde cholangiography for intrabiliary rupture of hydatid cyst. The American Journal of Surgery 191(2): 206210.

3. Balik A, Basoglu M, Celebi F, Oren D, Polat Y, et al. (1999) Surgical treatment of hydatid disease of the liver. Arch Surg 134(2): 166-169.

4. Magistrelli P, Masetti R, Coppola R, Messia A, Nuzzo G, et al. (1991) Surgical treatment of hydatid disease of the liver. Arch Surg 126(4): 518-523.

5. Demirci S, Eraslan S, Anadol E, Bozatli L (1989) Comparison of the results of different surgical techniques in the management of hydatid cysts of the liver. World J Surg 13(1): 88-91.

6. Lewall DB, McCorkell SJ (1986) Rupture of echinococcal cysts: diagnosis, classification and clinical implications. AJR Am J Roentgenol 146(2): 391-394.

7. Sayek I, Yalin R, Sanag Y (1980) Surgical treatment of hydatid disease of the liver. Arch Surg 115(7): 847850.

8. (1971) Kayabali I: Sur la chirurgie des kystes hydatiques du foie. Lyon Chir 67: 327-329.

9. Vicente M, Garcia M, Marco S (1984) Endoscopic retrograde cholangiography (ERCP) and complicated hepatic hydatid cyst in the biliary tract. Endoscopy 16(3): 124-126.

10. Hilmioglu F, Karincaoglu M, Yilmaz S, Yildirim B, Kirimlioglu V, et al. (2001) Complete Treatment of Ruptured Hepatic Cyst into Biliary Tree by ERCP. Digestive Diseases and Sciences 46(3): 463-467.

11. Al Karawi MA, Yasawy MI, El Shiekh MAR (1991) Endoscopic management of biliary hydatid disease: Report on six cases. Endoscopy 23(5): 278-281.

12. Beyrouti MI, Kharrat M, Elleuch S, Affes N, Gargouri F, et al. (2001) Drainage interne transfistulo-oddien des 


\section{Medical Journal of Clinical Trials \& Case Studies}

kystes hydatiques ouverts dans les voies biliares. Press Med 30: 1863-1867.

13. Bouzidi A, Chehab F (1997) Traitment chirurgical des fistules bilio-kystiques d'origine hydatique. A propos de 83 cases. J Chir 134(3): 114-118.

14. Mentes A, Yuzer Y, Ozbal O, Coker A, Ilter T, et al. (1993) Omentoplasty versus introflexion for hydatid liver cysts. J R Coll Surg Edinb 38(2): 82-85.

15. Aktan AO, Yalin R, Yegen C, Okboy N (1993) Surgical treatment of hepatic hydatid cysts. Acta Chir Belg 93(4): 151-153.

16. Dumas R, Le Gall P, Hastier P, Buckley MJ, Conio M, et al. (1999) The role of endoscopic retrograde cholangiopancre- atography in the management of hepatic hydatid disease. Endoscopy 31(3): 242-247.

17. Al Karawi MA, El Shiekh MAR, Yasawy MI (1990) Advances in diagnosis and management of hydatid disease. Hepato-Gastroenterol 37(3): 327-331.

18. Al Karawi MA, El Shiekh MAR, Yasawy MI, Haleem A (1987) Non-surgical endoscopic transpapillary treatment of ruptured echinococcus liver cyst obstructing the biliary tree. Endoscopy 19(2): 81-83.

19. Morris DL (1994) Echinococcus of the liver. Gut 35(11): 1517-1518. 